\title{
A Surgery Trainee's Guide to Writing a Manuscript
}

Tiffany W. Liang, MD ${ }^{a, b}$, David V. Feliciano, MD, FACS ${ }^{a, c}$, Leonidas G. Koniaris, MD, MBA, FACS ${ }^{a, d}$

aDepartment of Surgery, Indiana University School of Medicine, 545 Barnhill Drive, Emerson Hall 203, Indianapolis, IN 46202, USA

btifchang@iupui.edu, ${ }^{\circ}$ davfelic@iupui.edu, dIkoniari@iu.edu

\section{Corresponding author:}

Leonidas G. Koniaris, MD, MBA, FACS

Department of Surgery

Indiana University School of Medicine

550 N. University Blvd., UH 1295

Indianapolis, IN 46202

Phone: +1-317-274-4967

Fax: +1-317-274-0241

E-mail: lkoniari@iu.edu

This is the author's manuscript of the article published in final edited form as: 


\section{ABSTRACT}

Publishing clinical and research work for dissemination is a critical part of the academic process. Learning how to write an effective manuscript should be a goal for medical students and residents who hope to participate in publishing. While there are a number of existing texts that address how to write a manuscript, there are fewer guides that are specifically targeted towards surgery trainees. This review aims to direct and hopefully encourage surgery trainees to successfully navigate the process of converting ideas into a publication that ultimately helps understanding and improves the care of patients. 


\section{SHORT SUMMARY}

Academic work is integral to progress in the surgical field. This review guides the surgical trainee through the process of scholarly writing for submission to peer-reviewed journals. 


\section{KEYWORDS}

Scholarly writing

Surgery training

Writing guide

Academic productivity

Research

Publishing 


\section{INTRODUCTION}

One of the core purposes of physicians and surgeons is to improve human life through the application and advancement of medical science. This can be done not only by treating patients in the clinical setting, but also by contributing to the fund of medical knowledge through innovative research that can lead to improved future therapies. Innovations in research, however, are not meaningful until they are shared with the general scientific community, such as through publication.

The objective of this article is to provide surgery trainees with an overview of how to report to the scientific literature through peer-reviewed publications. While there are many published manuscripts that address paper writing in general, there is less information that specifically targets the surgery trainee. Those who would like a more comprehensive guide on this subject are directed to a book edited by Schein and colleagues (1). Publications are expected and required for competitive residencies and fellowships, academic jobs, and ultimately promotion and tenure at academic institutions. While it can be extremely challenging for surgeons to find the time to perform research, write and successfully publish papers, the authors would argue that academic work in conjunction with direct patient care is essential to a surgeon's professional development. While there are other forms of academic work (e.g., book chapters, presentations at conferences), the focus here is on writing for publication in peer-reviewed journals. Figure 1 serves as a general flowchart guide to the creative writing process. As many of the points are based upon the empiric experiences of the authors, the article potentially may present biases of the authors. 


\section{BEFORE BEGINNING TO WRITE}

Before starting the actual writing process, there are certain preliminary considerations. First, the ideas and data that will be presented in the manuscript should generally be original and impactful. For research articles, this step should ideally be considered prior to beginning the data collection process. Recognizing if a project represents a new direction or a less interesting confirmation of existing ideas is important as one decides if a particular project is worth pursuing and for what journals it may be appropriate. The benefit of investing the time and effort required to publish a study that represents only confirmatory information should be carefully considered. Next, determining the type of article that best presents the finding(s) to the reader will direct its style and content. Deciding the target journal and authors would then follow. These steps are essential for building the foundation of the manuscript and will be described in further detail below.

\section{Ensure originality and impact of research}

If others have already reported what one plans to write, the first question to answer is what value is there in publishing the same findings? If there would be considerable value gained in a confirmatory paper, or if disagreement exists in the literature, this would support the undertaking of such a project. For example, if one has the opportunity to report a very large series regarding the treatment of a particular condition with multiple therapies, this frequently is of broad interest. Reporting complication rates and potential pitfalls of this condition related to different therapies will help guide treatment and should be well received. Furthermore, even if a topic is 
already discussed in the literature, there may be a certain aspect of the research that may be novel, providing new insights. This innovative "angle" of the research should be highlighted in the manuscript as well as in the correspondence to the journal where the manuscript will be submitted.

\section{Decide on type of article}

There are a variety of article types, depending on the type of information to be conveyed. These include research articles, review articles, techniques papers, letters to the editor, opinions, case reports or series, and other journal-specific formats, such as a quiz or interesting image. Each journal has a different profile of article types that it accepts. Usually this has to do with the scope of the journal - if its main purpose is to showcase the newest techniques in vascular surgery (i.e., techniques papers), then it will likely not accept a manuscript discussing a newly discovered biomarker in pancreatic cancer (i.e., research article), no matter how significant the findings are.

Research articles are generally considered the most difficult to complete, since these require experimentation and/or data collection and analysis prior to writing. Both basic science and clinical papers fall into this category. These articles will generally be partitioned into introduction, methods, results, and discussion/conclusion sections. Research articles and clinical reviews remain the mainstay of surgical journals. These articles are generally considered the most significant contributions any individual makes in their academic career.

Review articles are a good way for researchers to analyze the literature and develop a solid fund of knowledge in an area of interest. The information obtained through this process can often be used as a foundation for the background when 
composing related grants, lectures, theses, and research articles. Reviews will also help others unfamiliar with the subject get a quick overview of existing knowledge in that area $(2,3)$.

Techniques papers are used to showcase and describe a procedure or novel operative approach or, occasionally, an entirely new type of operation. While a wellwritten manuscript is a must for any type of paper, a clear description of how to perform the particular technique is invaluable in this type of article. Images, either photographs or well-drawn illustrations, are often better than text when describing a procedure. As retold by others, "Great paper, poor art - reject. Poor paper, great art - accept!" The emphasis in these articles is the technical approach, with a limited presentation of complications and long-term outcomes. Presentation format and appropriateness for specific journals should be considered carefully, as not all journals accept these types of articles.

Letters to the editor are written in response to an article published in a particular journal. They usually question the interpretation of a study or offer an alternative viewpoint. Furthermore, they can be used to disseminate data and ideas that otherwise might not be published (4). Finally, letters to the editor also allow an opportunity to cite relevant literature that the initial article may not have sufficiently referenced. Regarding promotion and tenure, however, many reviewers will not consider letters to the editor as equivalent to independent research articles. Thus, these articles can be an excellent adjunct to one's record of scholarly publication but, like case reports below, should be used judiciously. 
Case reports and related article types are written for interesting and unusual disease presentations, remarkable images that provide an excellent teaching opportunity, and/or some novel aspect of management. They can be single-patient reports, a small series of two or more similar cases, or include a more extensive review of cases previously reported in the literature (5). Regardless, case reports, in the authors' experience, can be difficult to publish, as numerous case reports may have already been written that encompass what one might think is novel, and reviewers may not consider the report interesting. Nonetheless, a case report that introduces a new idea that will contribute to better management of patients is more likely to be accepted.

Rather than considering only a case report as a way to share an interesting clinical case, there are numerous other article types, including opinion or editorial-type articles, image reports, and quiz articles that may be easier to publish and will allow the case to be presented. These are journal-specific and are not discussed in further detail here. Nonetheless, the reader is encouraged to review different journals and potentially consider these article types to report their case. Finally, the authors would stress that case reports and similar manuscripts, although potentially of interest, should generally not constitute the majority of one's academic productivity. Authors should try and focus on the other article types that are more highly regarded.

\section{Identify the ideal journal(s)}

When deciding which journal is best suited for a potential manuscript, three considerations are the scope, readership, and scholarly metrics of the journal. The scope of a journal refers to what types of articles and the topics the journal aims to publish. Often, the scope is linked to the aims, mission, or purpose of the journal. The 
readership is largely determined by the scope and should be taken into account when choosing a journal in order to ensure that one reaches the intended audience. Besides ensuring that the intended type of audience is reached - for example, surgeons instead of pediatricians - the size of the audience can be important as well. Journal citation metrics are one method of gauging the importance of a journal via a measure of the average number of times other articles have referenced articles in a specific journal. Journals with higher citation metrics are generally considered more prestigious and, therefore, reach a larger audience. Thus, it is desirable to publish one's article in a journal with a higher impact factor. The top 20 relevant journals in the surgical field are listed in order of ranking by impact factor in Table 1, as reported by the 2014 Journal Citation Reports ${ }^{\circledR}$ (Thomson Reuters, 2015). The Eigenfactor score is another method used to rank the significance of a journal and is also shown in this table. Eigenfactor is determined by not only taking into account the number of times a journal is cited by another journal, but also by the influence and prestige of the citing journal (6).

A good rule of thumb in considering a journal is to determine if it is indexed by Journal Citation Reports and recognized by the United States National Library of Medicine and National Institutes of Health shared website, PubMed commons (http://www.ncbi.nlm.nih.gov/pubmed). Another factor suggestive of quality is if a journal is supported by a scientific, medical or surgical society. While it may be more difficult to publish a manuscript in one of these peer-reviewed or refereed journals that are listed on PubMed and the Journal Citation Reports, the end result of the peer-review process in these journals will likely be a better paper that will be accessed more by other researchers. 
Many new journals will not be listed by PubMed or have a Journal Citation Report listing, as a journal must be out for at least a few years to generate such metrics. The Journal Citation Report provides metrics for approximately 11,700 journals. Thus, there arguably is not a need to publish in unlisted journals unless a particular project has been rejected from a number of journals listed. In some instances, the term "predatory journal" has been introduced for unlisted journals that have little or no peer-review process, are not indexed in these databases, and may offer publication for a fee. Publishing in such journals may prevent widespread dissemination of the manuscript and, therefore, fail to promote the goals of academic work (7).

\section{An algorithm for choosing appropriate journals}

How does one go about finding the right journal? Considering a top journal, such as listed in Table 1, would certainly be a good first choice. Another efficient method to search for a suitable journal is through search engine sites. A sample of such sites that are free of charge to the general public can be found in Table 2. These search engines are also good for identifying multiple candidate journals, in case one's first choice does not pan out. The journals identified by these sites, however, should always be further investigated to ensure suitability for the manuscript being submitted. Another caution is that some journal finder sites are geared only to journals affiliated with a particular publishing company. Therefore, their search results may not represent all possible relevant journals. In any case, consulting with a mentor and/or senior author is usually warranted for novice researchers. The authors' bias is also to use only journals that are referenced by Journal Citation Reports $®$ (Thomson Reuters), which allows sorting of journals by topic and impact factor. 


\section{Identifying the author(s)}

Authorship is important to determine early in the writing process, and it is suggested to be inclusive (8). The senior author should ultimately be responsible for who the authors are and the order in which their names are listed. If there is no senior author, then all co-authors should come to an agreement on the final decision. The first author(s) typically earns the title by contributing the most effort into developing the project, performing the data collection and analysis process, and/or writing the manuscript. The senior author, if different from the first author, is usually the person who takes responsibility for the paper overall and might be the mentor for the more junior first author. The corresponding author is responsible for communicating with the journal as well as with readers with questions or comments after publication. The senior and corresponding authors are often the same person. All authors should agree on the order of middle authors, which may be determined by order of contribution. A potentially useful scoring system to determine order of authorship has been proposed by Petroianu (9). It involves more heavily weighted criteria such as creation of the original idea and method as well as less heavily weighted items such as study funding and provision of materials (9).

Authorship can be a difficult issue. Familiarity with criteria for authorship is suggested and reviewed by the International Committee of Medical Journal Editors. Briefly, according to this committee, meeting the criteria for authorship requires that all authors have made considerable contributions to the following: (1) the conception and design of the work or to the collection, analysis, and interpretation of the generated data; (2) writing the manuscript or critically reviewing and revising it for intellectual 
content; and (3) approving the final version of the manuscript for publication (10). Some journals will require a description of each author's contributions. Any individual who does not meet all the criteria, but has contributed to the work, could alternatively be acknowledged at the end of the article (10). Simply having contributed cases or funding to a study, or providing materials or reagents for an experiment generally is considered insufficient to warrant authorship.

\section{WRITING}

Composing and refining the manuscript can be an intimidating undertaking, especially for the novice author. Over time, the process becomes easier. Initially, it is useful to focus one's thoughts and to approach writing the paper in manageable sections. The standardized format for research articles is discussed below in section titled "Parts of the Paper," as well as general guidelines for article sections. Finally, a review by a professional editor may be worthwhile to ensure that the information is presented in the most understandable way.

\section{Focus your thoughts}

It is essential to discuss and critically review data and ideas with co-authors and mentors. The paper's main point and how the findings and paper will impact the field of interest should be identified so that this might be more clearly conveyed in the manuscript. Authors should consider what to present and keep focused on a particular topic. Separating a paper with too broad of a scope into two or more focused papers should be considered. Similarly, authors should be clear regarding the type of article 
they are targeting; for example, authors should avoid combining a research article with a techniques or review paper.

\section{Parts of the paper}

Most papers have abstracts at the beginning that convey the main points of the article. The abstract structure may differ by journal and article type. For structured articles presenting original research, the abstract is generally composed of four sections: background and objectives, methods, results, and conclusions. Such distinct sections may not be appropriate for reviews or case reports; rather, a summary is adequate in these types of articles.

Research articles tend to follow the traditional introduction, methods, results, and discussion/conclusion sections format, otherwise known as "IMRAD (11-18)." Other article types may not follow the typical IMRAD format, but usually have introduction, body, and discussion/conclusion sections. Generally, the introduction consists of a few paragraphs that briefly describe the background of the project and why the paper is written. All manuscripts should ideally include how the work is novel and/or how it hopes to impact patient care. The methods section describes the approach of the project and how the data collection and analyses were performed, as well as details of any relevant procedures and materials. The results section describes the information that is generated from data collection and analyses and may include the initial interpretation of this information. The discussion section consolidates the project's findings and interpretations of its results, and it might include suggestions on how these findings can impact patient care. The conclusion section should also discuss how the study findings should be incorporated into models of current understanding as well as discuss 
limitations around the interpretation of the data presented. Future directions of research are also generally included in this section. Finally, the discussion might end with a takehome message.

Most scholarly articles reference other publications and, therefore, will have a reference or bibliography section at the end. The number of references and its citation style will be dictated by the journal that the article will be submitted to. Using a reference manager (i.e., a software program that automates organization of citations) is helpful, as it can usually automatically format the references to journal-specific requirements. This feature is especially useful when resubmitting the same article to a different journal.

Additional items include tables and figures that are referenced in the manuscript or supplementary material (usually additional figures and tables, or miscellaneous methods that further clarify those mentioned in the main text) that could not be included in the main article. Authors can always consider hiring a professional artist or using computer software to generate informative, professional appearing illustrations. All photos should be of high quality.

It is worth mentioning that the order of writing may not follow the order in which the sections of the paper were described above. It might make more sense to start with writing the methods and results, then move on to the introduction and discussion, possibly after discussions with co-authors and others regarding the study's significance. Completion of the abstract may be considered once all the sections are relatively finalized. Alternatively, the abstract may actually be the first item that one writes as it will then serve as a guide for the rest of the paper, especially if submitting an abstract to a conference prior to the actual writing of the manuscript. 


\section{ETHICS OF WRITING}

As with all academic endeavors, one should abide by a basic code of ethics when writing a manuscript. Most would agree that plagiarism, or reproducing others' work (their ideas even more so than merely their words (19)) as your own, is a blatant violation of ethical conduct.

Self-plagiarism, however, appears to be less commonly defined and is often misunderstood. Having more than $30 \%$ of two or more of your own published works matching in text is one useful definition of self-plagiarism (20). This concept, however, also involves more nuanced characterizations. Mohapatra and Samal have suggested that there are 3 types of self-plagiarism: (1) publishing two (or more) manuscripts that have the same data but with different words; (2) splitting up one larger study into separate publications in order to increase the number of publications, even though the larger study would make more sense or better support the findings (i.e., "salami publications"); and (3) using text from one's own previously published work in a new work (21). To further clarify the second point, the key is whether the intent is merely to obtain more publications or if it is to improve the paper. For example, the authors of this manuscript would argue that dividing up a manuscript because a topic is too broad is not an example of ethical misconduct, since a large combined manuscript would add unnecessary confusion to the reader and does not add value to the results. In any case, deception is the distinguishing factor of self-plagiarism $(20,22)$, as it is for any form of plagiarism. 
In order to screen for possible cases of plagiarism, many journals use software services such as iThenticate (http://www.ithenticate.com/). For a fee, authors themselves can also access this service, as it is useful to check even for unintentional plagiarism or self-plagiarism.

Dealing with a conflict of interest is a separate ethical issue. As one section editor of the Journal of Investigative Dermatology wrote in an editorial, it is defined as having "a set of conditions [that] is operating that could have a marked influence on behavior (23)." Having a conflict of interest by itself is not necessarily problematic, but rather it is the failure to disclose that has ethical implications $(15,23)$. Transparency, disclosure, and peer review are good ways to address conflicts of interest, whether financial or personal in nature (24).

Lastly, the topic of self-citation should be mentioned. It is certainly acceptable and even required when referring to previous relevant work (to avoid deception in selfplagiarism), but authors should exercise restraint. This practice can artificially give the appearance of increased academic productivity and, therefore, be an ethical dilemma. Moreover, excess self-citations may not be well received by reviewers and are improper if the citation of work of others may be more appropriate.

\section{CONCLUSION}

Everyone from students to senior surgeons should advance their personal and professional development as well as the field of science and medicine at large. Even if a trainee decides not to be involved in research in the future, at least he or she is familiar 
with the process of writing and has the ability to more critically assess the scientific literature. It can be argued that it makes one a better physician and surgeon over time. 


\section{DISCLOSURES AND ACKNOWLEDGEMENTS}

Conflicts of interest: none.

Funding sources: This research did not receive any specific grant from funding agencies in the public, commercial, or not-for-profit sectors. 


\section{REFERENCES}

1. Schein M, Farndon JR, Fingerhut A. A Surgeon's Guide to Writing and Publishing. Shropshire, UK: TFM Publishing Ltd; 2001. 288 p.

2. McKillop IH, Moran DM, Jin X, Koniaris LG. Molecular pathogenesis of hepatocellular carcinoma. The Journal of surgical research. 2006 Nov;136(1):125-35. PubMed PMID: 17023002. Epub 2006/10/07. eng.

3. Koniaris LG, McKillop IH, Schwartz SI, Zimmers TA. Liver regeneration. Journal of the American College of Surgeons. 2003 Oct;197(4):634-59. PubMed PMID: 14522336. Epub 2003/10/03. eng.

4. Zimmers TA, Pierce RH, McKillop IH, Koniaris LG. Resolving the role of IL-6 in liver regeneration. Hepatology (Baltimore, Md). 2003 Dec;38(6):1590-1; author reply 1. PubMed PMID: 14647070. Epub 2003/12/03. eng.

5. Altinors $\mathrm{N}$. The structure of a neurosurgical manuscript. Acta neurochirurgica Supplement. 2002;83:115-20. PubMed PMID: 12442631. Epub 2002/11/22. eng. 6. Bergstrom C. Eigenfactor. College and Research Libraries News. 2007;68(5):314-6 .

7. Moher D, Srivastava A. You are invited to submit. BMC medicine. 2015;13:180. PubMed PMID: 26239633. Pubmed Central PMCID: Pmc4524126. Epub 2015/08/05. eng.

8. Koniaris LG, Coombs MI, Meslin EM, Zimmers TA. Protecting Ideas: Ethical and Legal Considerations When a Grant's Principal Investigator Changes. Science and engineering ethics. 2015 Jul 31. PubMed PMID: 26228741. Epub 2015/08/01. Eng. 
9. Petroianu A. Distribution of authorship in a scientific work. Arquivos brasileiros de cirurgia digestiva : $A B C D=$ Brazilian archives of digestive surgery. 2012 JanMar;25(1):60-4. PubMed PMID: 22569982. Epub 2012/05/10. Eng Por.

10. UNiform requirements for manuscripts submitted to biomedical journals. Jama. 1997;277(11):927-34.

11. Baker PN. How to write your first paper. Obstetrics, Gynaecology \& Reproductive Medicine. 2012 3//;22(3):81-2.

12. Cetin S, Hackam DJ. An Approach to the Writing of a Scientific Manuscript1. Journal of Surgical Research. 2005 10//;128(2):165-7.

13. Davidson A, Delbridge E. How to write a research paper. Paediatrics and Child Health. 2012 2//;22(2):61-5.

14. El-Serag HB. Scientific manuscripts: the fun of writing and submitting. Gastrointestinal Endoscopy. 2006 12//;64(6, Supplement):S19-S22.

15. Johnson TM. Tips on how to write a paper. Journal of the American Academy of Dermatology. 2008 12//;59(6):1064-9.

16. Manske PR. Structure and Format of Peer-Reviewed Scientific Manuscripts. The Journal of Hand Surgery. 2006 9//;31(7):1051-5.

17. Vintzileos AM, Ananth CV. How to write and publish an original research article. American Journal of Obstetrics and Gynecology. 2010 4//;202(4):344.e1-.e6.

18. Singer AJ, Hollander JE. How to Write a Manuscript. The Journal of Emergency Medicine. 2009 1//;36(1):89-93. 
19. Bouville M. Plagiarism: words and ideas. Science and engineering ethics. 2008 Sep;14(3):311-22. PubMed PMID: 18368537. Epub 2008/03/28. eng.

20. Marik PE. Self-plagiarism: the perspective of a convicted plagiarist! European journal of clinical investigation. 2015 Jun 25. PubMed PMID: 26110581. Epub 2015/06/26. Eng.

21. Mohapatra S, Samal L. The ethics of self-plagiarism. Asian journal of psychiatry. 2014 Dec;12:147. PubMed PMID: 25466781. Epub 2014/12/04. eng.

22. Bonnell DA, Hafner $\mathrm{JH}$, Hersam MC, et al. Recycling is not always good: the dangers of self-plagiarism. ACS nano. 2012 Jan 24;6(1):1-4. PubMed PMID: 22268423. Epub 2012/01/25. eng.

23. Williams HC. Full disclosure--nothing less will do. The Journal of investigative dermatology. 2007 Aug;127(8):1831-3. PubMed PMID: 17632552. Epub 2007/07/17. eng.

24. Caplan AL. Halfway there: the struggle to manage conflicts of interest. The Journal of clinical investigation. 2007 Mar;117(3):509-10. PubMed PMID: 17332876. Pubmed Central PMCID: Pmc1804343. Epub 2007/03/03. eng. 
Table 1. Top 20 surgical journals ranked by impact factor (2014 Journal Citation Reports ${ }^{\circledR}$, Thomson Reuters, 2015).

\begin{tabular}{|clccc|}
\hline Rank & \multicolumn{1}{c}{ Journal } & $\begin{array}{c}\text { Total } \\
\text { cites }\end{array}$ & $\begin{array}{c}\text { Impact } \\
\text { factor }\end{array}$ & $\begin{array}{c}\text { Eigenfactor } \\
\text { score }\end{array}$ \\
\hline 1 & Annals of Surgery & 41468 & 8.327 & 0.07481 \\
\hline 2 & $\begin{array}{l}\text { Journal of Neurology Neurosurgery } \\
\text { and Psychiatry }\end{array}$ & 25650 & 6.807 & 0.03499 \\
\hline 3 & $\begin{array}{l}\text { Journal of Heart and Lung } \\
\text { Transplantation }\end{array}$ & 8562 & 6.650 & 0.02437 \\
\hline 4 & American Journal of Transplantation & 18092 & 5.683 & 0.05320 \\
\hline 5 & British Journal of Surgery & 20540 & 5.542 & 0.03445 \\
\hline 6 & $\begin{array}{l}\text { Journal of Bone and Joint Surgery - } \\
\text { American Volume }\end{array}$ & 37434 & 5.280 & 0.04747 \\
\hline 7 & $\begin{array}{l}\text { American Journal of Surgical } \\
\text { Pathology }\end{array}$ & 18910 & 5.145 & 0.03022 \\
\hline 8 & $\begin{array}{l}\text { Journal of the American College of } \\
\text { Surgeons }\end{array}$ & 13352 & 5.122 & 0.03631 \\
\hline 9 & Endoscopy & 8546 & 5.053 & 0.01610 \\
\hline 10 & Archives of Surgery & 13280 & 4.926 & 0.01880 \\
\hline 11 & Liver Transplantation & 9357 & 4.241 & 0.01762 \\
\hline 12 & $\begin{array}{l}\text { Journal of Thoracic and } \\
\text { Cardiovascular Surgery }\end{array}$ & 23757 & 4.168 & 0.05431 \\
\hline 13 & $\begin{array}{l}\text { Surgery for Obesity and Related } \\
\text { Diseases }\end{array}$ & 3158 & 4.066 & 0.00940 \\
\hline 14 & JAMA Surgery & 785 & 3.936 & 0.00371 \\
\hline 15 & Annals of Surgical Oncology & 19490 & 3.930 & 0.05779 \\
\hline 16 & Annals of Thoracic Surgery & 32052 & 3.849 & 0.06305 \\
\hline 17 & Transplantation & 24021 & 3.828 & 0.03823 \\
\hline 18 & Diseases of the Colon \& Rectum & 13256 & 3.749 & 0.01911 \\
\hline 19 & Obesity Surgery & 9098 & 3.747 & 0.01661 \\
\hline 20 & Journal of Neurosurgery & 29516 & 3.737 & 0.03310 \\
\hline & $\quad$ & & \\
\hline
\end{tabular}


Table 2. Journal search engines.

\begin{tabular}{|c|c|c|c|}
\hline Search Engine & Website(s) & Input options & Output \\
\hline $\begin{array}{l}\text { Elsevier Journal } \\
\text { Finder }\end{array}$ & http://journalfinder.elsevier.com/ & $\begin{array}{l}\text { Title } \\
\text { Abstract } \\
\text { Fields of research } \\
\text { Open access filter }\end{array}$ & $\begin{array}{l}\text { Journal name } \\
\text { Confidence of match } \\
\text { Impact factor } \\
\text { Open access, fee } \\
\text { Editorial time } \\
\text { Acceptance rate } \\
\text { Production time } \\
\text { Embargo period } \\
\text { Scope and related information }\end{array}$ \\
\hline $\begin{array}{l}\text { Journal/Author } \\
\text { Name Estimator } \\
\text { (JANE) }\end{array}$ & http://biosemantics.org/jane/index.php & $\begin{array}{l}\text { Title } \\
\text { Abstract } \\
\text { Keywords } \\
\text { Language } \\
\text { Publication type } \\
\text { Open access options } \\
\text { PubMed Central filter }\end{array}$ & $\begin{array}{l}\text { Confidence of match } \\
\text { Journal name } \\
\text { Open access } \\
\text { Article Influence score } \\
\text { Similar articles }\end{array}$ \\
\hline $\begin{array}{l}\text { Springer/ BioMed } \\
\text { Central/ Chemistry } \\
\text { Central Journal } \\
\text { Selector }\end{array}$ & $\begin{array}{l}\text { http://www.springeropen.com/authors/authorfaq/findout } \\
\text { http://www.biomedcentral.com/authors/authorfaq/findout } \\
\text { http://www.chemistrycentral.com/authors/authorfaq/findo } \\
\underline{\text { ut }}\end{array}$ & $\begin{array}{l}\text { Abstract } \\
\text { Impact factor filter } \\
\text { Open access filter }\end{array}$ & $\begin{array}{l}\text { Confidence of match } \\
\text { Journal name } \\
\text { Impact factor } \\
\text { Frequency } \\
\text { Publishing model (e.g. open access) }\end{array}$ \\
\hline $\begin{array}{l}\text { Web of Science }{ }^{\mathrm{TM}} \\
\text { Journal Citation } \\
\text { Reports } ₫\end{array}$ & http://about.jcr.incites.thomsonreuters.com/ & $\begin{array}{l}\text { Journal category } \\
\text { Impact factor range } \\
\text { Publisher } \\
\text { JCR year } \\
\text { Open access filter }\end{array}$ & $\begin{array}{l}\text { Journal name } \\
\text { Total cites } \\
\text { Impact factor } \\
\text { Eigenfactor score }\end{array}$ \\
\hline
\end{tabular}

JCR, Journal Citation Reports. 
